\title{
ISOFLAVONAS EM PRODUTOS COMERCIAIS DE SOJA ${ }^{1}$
}

\author{
Silvana Pedroso de GÓES-FAVONI², Adelaide Del Pino BELÉIA ${ }^{2, *}$, \\ Mercedes C. CARRÃO-PANIZZI ${ }^{3}$, José Marcos Gontijo MANDARINO³
}

\section{RESUMO}

Isoflavonas, associadas ao consumo de proteína de soja, constituem um grupo de substâncias envolvidas em atividades anti-carcinogênicas, na redução da perda de massa óssea e na diminuição do colesterol do sangue. A concentração de isoflavonas foi determinada em produtos comerciais à base de soja produzidos no Brasil. Foram analisados cinco farinhas de soja (FS), quatro proteínas texturizadas (PTS), dois extratos hidrossolúveis (EH) e quatro formulados infantis (FI). A extração foi com etanol e ácido acético e a quantificação e identificação das isoflavonas foram realizadas por CLAE. Em farinha de soja e em proteína texturizada predominaram os compostos malonil-conjugados. Farinha de soja (96mg de agliconas equivalentes/100g) e PTS (70mg de agliconas equivalentes/100g), obtidas a partir da mesma cultivar apresentaram diferenças na concentração e distribuição dos isômeros devido ao processamento. Extratos hidrossolúveis e formulados infantis apresentaram agliconas, variando de $8 \%$ a $28 \%$ do total de isoflavonas, mas os principais isômeros foram os $\beta$-glicosídios. O consumo diário de $25 \mathrm{~g}$ de proteína de farinha de soja integral ou de PTS contribuem com mais de $50 \mathrm{mg}$ de isoflavonas totais na dieta. Em formulados infantis a concentração de isoflavonas totais foi menor que nos demais produtos devido à adição de ingredientes não derivados de soja.

Palavras-chave: soja; isoflavonas; alimentos à base de soja; compostos funcionais.

\section{SUMMARY}

ISOFLAVONES IN COMMERCIAL SOY FOODS. Isoflavones, associated with soy protein consumption, constitute a group of substances involved in anti-carcinogenic activity, reduction of the loss of bone mass and decrease of blood cholesterol, are considered functional compounds. Isoflavones in commercial soy foods produced in Brazil were determined. Five soy flours (SF), four textured vegetable proteins (TVP), two hydro soluble extracts (HE) and four formulated infant foods (IF) were analyzed. Isoflavone extraction was with ethanol and acetic acid and quantification and identification were accomplished by HPLC. Soy flour and textured vegetable protein contained mostly conjugated malonyl-glucosides, a SF (96mg of aglycons equivalent/100g) and TVP (70mg of aglycons equivalent / 100g), obtained from the same cultivar were different in concentration and distribution of the compounds due to processing conditions. Hydro soluble extracts and formulated infant foods had aglucones varying from $8 \%$ to $28 \%$ of the total isoflavones, but the predominant isomers were $\beta$-glucosides. Twenty-five grams of soy protein a day, from SF or TVP, contribute with more than the recommended consumption of $50 \mathrm{mg}$ of total isoflavones a day. In the formulated infant food the concentration of total isoflavones was lower than in the other products due to addition of other ingredients.

Keywords: Glycine max, soybean; isoflavones; soy foods; functional foods.

\section{1 - INTRODUÇÃO}

O consumo de soja [Glycine max (L.) Merrill] e derivados tem sido associado a redução do risco de doenças crônicas [15, 16]. As isoflavonas, compostos fenólicos encontrados na soja, estão envolvidas em atividade anti-carcinogênica, redução da perda de massa óssea e diminuição do colesterol sérico $[1,11,12,16,21]$. As isoflavonas compreendem as agliconas daidzeína, genisteína e gliciteína, os respectivos $\beta$-glicosídios e os conjugados malonil-glicosídios e acetil-glicosídios [10]. A concentração de isoflavonas nos grãos de soja é geneticamente controlada e influenciada pelas condições ambientais, sendo a temperatura durante o desenvolvimento do grão o fator mais importante [5, 22]. Segundo CARRÃO-PANIZZI et al. [6], soja plantada em regiões com temperaturas médias de $20^{\circ} \mathrm{C}$ apresentaram concentração média de isoflavonas de $147,8 \mathrm{mg} / 100 \mathrm{~g}$ (FTAbyara) e 180,1mg/100g (IAS 5) e quando plantadas em

\footnotetext{
1. Recebido para publicação em 07/01/2003. Aceito para publicação em 22/07/2004 (001045).

2. Universidade Estadual de Londrina, UEL, Depto.de Tecnologia de Alimentos e Medicamentos, Cx. Postal 6001, CEP 86051-990, Londrina, PR, Brasil.

3. Centro Nacional de Pesquisa da Soja - EMBRAPA Soja, Caixa Postal 231, CEP 86001-970, Londrina, PR, Brasil.

* A quem a correspondência deve ser enviada.
}

regiões com temperatura média de $25^{\circ} \mathrm{C}$ apresentaram $73,5 \mathrm{mg} / 100 \mathrm{~g}$ e $85,5 \mathrm{mg} / 100 \mathrm{~g}$, respectivamente.

As isoflavonas também estão presentes em alimentos à base de soja, como tofu, miso e tempeh, 33,7mg, 29,4 e 62,5mg/100g (b. u.), respectivamente, que são consumidos há milhares de anos por asiáticos e que constituem uma fonte destas substâncias [25]. No Brasil, segundo produtor mundial de soja, cerca de $70 \%$ do farelo de soja é destinado à exportação e os 30\% restantes utilizados em ração animal e uma proporção reduzida como matéria-prima industrial na forma de isolados e concentrados protéicos. O processamento da soja dá origem a diferentes matérias-primas como farinhas de soja, extratos hidrossolúveis e proteínas texturizadas que podem ser utilizados na produção de alimentos que fazem parte da dieta ocidental [9, 24]. Nos últimos anos, a procura por alimentos derivados de soja tem aumentado devido a divulgação dos benefícios à saúde atribuídos ao consumo desta leguminosa.

A presença e a concentração das isoflavonas nos produtos à base de soja dependem das condições de processamento, principalmente a temperatura de tratamento do material $[8,25]$. Produtos não-fermentados têm concentrações de isoflavonas duas a três vezes maiores que produtos fermentados [25], entretanto, a distribuição dos constituintes difere nestes dois gru- 
pos: produtos fermentados apresentam predominantemente agliconas enquanto os produtos não-fermentados apresentam maiores concentrações de $\beta$-glicosídios [7]. Segundo SONG et al. [20], o teor de isoflavonas na maioria dos alimentos à base de soja varia de 100 a $300 \mathrm{mg} / 100 \mathrm{~g}$.

Com o crescente aumento da procura por alimentos à base de soja no Brasil, diversos produtos têm sido lançados no mercado e, pouco se conhece quanto à presença e concentração das isoflavonas. Este trabalho teve como objetivo quantificar isoflavonas em produtos comerciais (farinhas de soja, proteína texturizada de soja - PTS e extratos hidrossolúveis de soja) produzidos no Brasil.

\section{2 - MATERIAL E MÉTODOS}

\section{1- Matéria-prima}

Alimentos formulados e ingredientes derivados de soja analisados quanto ao teor de isoflavonas foram obtidos diretamente dos fornecedores ou adquiridos em mercados da cidade de Londrina (PR). Foram analisados cinco tipos de farinhas de soja (FS) e quatro tipos de proteína texturizada (PTS), processadas pela Nutrimental S. A. e Perdigão S/A, dois extratos hidrossolúveis em pó (EH) e quatro tipos de formulados infantis (FI), que são extratos hidrossolúveis acrescidos de outros ingredientes além dos derivados de soja, produzidos pela Olvebra Industrial S/A (Tabela 1).

TABELA 1. Produtos comerciais à base de soja analisados quanto ao teor de isoflavonas.

\begin{tabular}{lll}
\hline Tipo & Amostra & \multicolumn{1}{c}{ Descrição } \\
\hline & 1 & Farinha de soja desengordurada \\
FS & 2 & Farinha de soja integral, enzimas ativos \\
& 3 & Farinha de soja integral, enzimas ativos \\
& 4 & Farinha de soja integral submetida a tratamento térmico \\
& 5 & Farinha de soja integral submetida a tratamento térmico \\
& & \\
& 1 & PTS de farinha de soja desengordurada \\
& 2 & PTS de farinha de soja desengordurada \\
& 3 & PTS de farinha de soja tostada \\
& 4 & PTS de farinha de soja desengordurada \\
& & \\
& 1 & Formulado à base de proteína isolada de soja \\
& 2 & Formulado à base de extrato de soja desengordurada \\
& 3 & Formulado à base de farelo de soja desengordurado \\
& 4 & Formulado à base de farelo de soja desengordurado e fibras insolúveis \\
& & \\
& &
\end{tabular}

FS=farinhas; PTS= proteinas texturizadas; $\mathrm{FI}=$ formulados infantis; $\mathrm{EH}=$ extrato hidrossolúveis.

\section{2 - Análise de isoflavonas}

Cem miligramas de cada amostra foram colocadas em tubos de ensaio com $4 \mathrm{~mL}$ de etanol 70\% e 0,1\% de ácido acético. Os tubos permaneceram em temperatu- ra ambiente por 1 hora sob agitação constante (mesa agitadora a 250rpm - Orbital Tecnal Mod. TE140) [10]. Após a extração, $1,5 \mathrm{~mL}$ do extrato foi transferido para “eppendorff" e centrifugado por 10 minutos a 13.500rpm a temperatura de $5^{\circ} \mathrm{C}$ (Centrifuga Eppendorf mod. $5417 \mathrm{R})$. Alíquotas de $100 \mu \mathrm{l}$ do sobrenadante foram transferidas para os tubos do auto-injetor do cromatógrafo Waters 2690. A separação das isoflavonas foi realizada em coluna de fase reversa ODS C-18 (YMC-Pack ODS-AM, S-5mm, 120 A, com diâmetro de $4.6 \mathrm{~mm}$ e $250 \mathrm{~mm}$ de comprimento). A fase móvel foi formada por um gradiente de acetonitrila com $0,1 \%$ de ácido acético (solvente A) e água com $0,1 \%$ de ácido acético (solvente B). A condição inicial foi de $20 \%$ para o solvente A, atingindo $50 \%$ de concentração de A em 20 minutos, passando a $100 \%$ e permanecendo por 5 minutos, retornando a $20 \%$ nos últimos 15 minutos, seguindo a metodologia de KUDOU et al. [10]. Foi utilizado detector de arranjo de diodo Waters 996, ajustado para o comprimento de onda de 260nm. Padrões de daidzina, daidzeína, genistina e genisteína (Fujicco) foram utilizados na concentração de $0,0125 \mathrm{mg} / \mathrm{mL}$. Os conjugados malonil-glicosídios foram calculados com base em seus pesos moleculares [21] e o total de isoflavonas foi calculado como agliconas usando-se os diferentes pesos moleculares de cada constituinte analisado.

\section{3 - Análise estatística}

Os resultados foram avaliados por análise de variância (ANOVA) e teste de Tukey [23] quando adequado, com nível de significância de $5 \%$ de probabilidade, utilizando o programa Statistical Analysis System, SAS [18].

\section{3 - RESULTADOS E DISCUSSÃO}

\section{1 - Farinhas e texturizados protéicos de soja}

O teor de isoflavonas totais bem como a distribuição dos compostos apresentaram variações entre os produtos analisados. Nas farinhas integrais de soja FS 2 e FS 3, obtidas a partir da moagem de grãos de soja, as formas conjugadas malonil-glicosídicas foram predominantes: 59\% e 79\%, respectivamente (Tabela 2). Segundo COWARD et al. [7], em produtos de soja minimamente processados como farinha de soja integral, os conjugados malonil-glicosídios foram os compostos encontrados em maiores concentrações que as demais isoflavonas, assim como em grãos de soja.

As farinhas de soja FS 1 e FS 2 são provenientes do mesmo fabricante e a diferença encontrada nos teores de isoflavonas se deve ao processo de desengorduramento da farinha FS 1, que concentra isoflavonas na fração não lipídica. Segundo COWARD et al. [7], extração de óleo promove a concentração dos demais constituintes químicos, uma vez que as isoflavonas não são encontradas no óleo de soja [17]. As farinhas FS 3, FS 4 e FS 5 foram obtidas a partir de grãos da mesma cultivar sob as mesmas condições ambientais durante o desenvolvimento dos grãos, entretanto, segundo o fa- 
bricante, as farinhas FS 4 e FS 5 foram submetidas a tratamento térmico para inativação dos sistemas enzimáticos (lipoxigenases, ureases, peroxidases) e de inibidores de tripsina. Os tratamentos térmicos elevaram as concentrações de $\beta$-glicosídios e agliconas, enquanto compostos malonil tiveram a concentração reduzida, em relação a FS3.

Nas farinhas FS 4 e FS 5, o teor de malonil-glicosídeos (77,8 e $81,5 \mathrm{mg} / 100 \mathrm{~g}$, respectivamente) foi menor que na farinha FS $3(147,7 \mathrm{mg} / 100 \mathrm{~g})$, enquanto o teor de agliconas e $\beta$-glicosídios, principalmente genistina, foi maior (Tabela 2). Em produtos à base de soja a distribuição dos compostos de isoflavonas depende das condições de processamento, principalmente a temperatura de tratamento do material [25]. As formas malonilglicosídicas são termicamente instáveis, sofrendo hidrólise pela ação de temperaturas acima de $80^{\circ} \mathrm{C}$ [10], dando origem às formas $\beta$-glicosídicas [4]. Quanto aos teores de isoflavonas totais apresentados pelas farinhas FS 3, FS 4 e FS 5 a diferença, apresentada pelos valores reduzidos em FS4 e FS5, podem ser devido à formação de conjugados acetil-glicosídios a partir da descarboxilação dos conjugados malonil-glicosídios. Segundo BARNES, KIEK \& COWARD [4], os malonil-glicosídios pela ação de calor podem dar origem aos $\beta$-glicosídios e acetilglicosídios. Os conjugados acetil-glicosídios não foram analisados neste trabalho.

WANG \& MURPHY [24] analisaram os 12 compostos de isoflavonas em farinhas de soja e encontraram $110 \mathrm{mg}$ de isoflavonas totais/100g de farinha, pois os acetis derivados e os compostos de glicitina estavam presentes em quantidades reduzidas, enquanto malonil genistina era o composto em maior concentração. COWARD et al. [8] analisaram a presença dos 12 compostos de isoflavonas, e encontraram 130mg de isoflavonas totais/100 g de farinha de soja, sendo o composto em maior concentração os malonil glicosidios.

TABELA 2. Teor de isoflavonas (mg/100g) em farinhas de soja comerciais.

\begin{tabular}{cccccccc}
\hline Produto & Daidzina & Genistina & $\begin{array}{c}\text { Malonil- } \\
\text { Daidzina }\end{array}$ & $\begin{array}{c}\text { Malonil- } \\
\text { Genistina }\end{array}$ & Daidzeína & Genisteína & Total $^{*}$ \\
\hline FS 1 & $55,7 \mathrm{a}$ & $65,3 \mathrm{a}$ & $54,9 \mathrm{~b}$ & $103,9 \mathrm{a}$ & $4,9 \mathrm{a}$ & $6,1 \mathrm{a}$ & 168 \\
& $( \pm 3,2)$ & $( \pm 2,2)$ & $( \pm 4,3)$ & $( \pm 3,0)$ & $( \pm 0,2)$ & $( \pm 0,2)$ & \\
FS 2 & $41,4 \mathrm{~b}$ & $39,7 \mathrm{~b}$ & $68,2 \mathrm{a}$ & $89,6 \mathrm{~b}$ & $3,4 \mathrm{~b}$ & $3,3 \mathrm{~b}$ & 138 \\
& $( \pm 3,4)$ & $( \pm 3,4)$ & $( \pm 2,8)$ & $( \pm 7,3)$ & $( \pm 0,3)$ & $( \pm 0,5)$ & \\
FS 3 & $11,5 \mathrm{~d}$ & $14,2 \mathrm{e}$ & $54,6 \mathrm{~b}$ & $93,1 \mathrm{~b}$ & $1,3 \mathrm{e}$ & $2,7 \mathrm{bc}$ & 96 \\
& $( \pm 0,6)$ & $( \pm 0,5)$ & $( \pm 1,2)$ & $( \pm 3,8)$ & $( \pm 0,1)$ & $( \pm 0,1)$ & \\
FS 4 & $15,7 \mathrm{~cd}$ & $21,2 \mathrm{~d}$ & $30,5 \mathrm{c}$ & $47,3 \mathrm{c}$ & $1,9 \mathrm{~d}$ & $1,5 \mathrm{~d}$ & 65 \\
& $( \pm 0,5)$ & $( \pm 0,4)$ & $( \pm 0,4)$ & $( \pm 0,9)$ & $( \pm 0,1)$ & $( \pm 0,1)$ & \\
FS 5 & $19,8 \mathrm{c}$ & $29,0 \mathrm{c}$ & $31,7 \mathrm{c}$ & $49,8 \mathrm{c}$ & $3,3 \mathrm{~b}$ & $2,3 \mathrm{c}$ & 78 \\
& $( \pm 1,1)$ & $( \pm 1,5)$ & $( \pm 1,8)$ & $( \pm 2,7)$ & $( \pm 0,1)$ & $( \pm 0,1)$ & \\
\hline
\end{tabular}

Médias de três repetições e desvio padrão $( \pm \mathrm{DP})$, em base seca. Médias seguidas pelas mesmas letras minúsculas nas colunas não diferem entre si pelo teste de Tukey $(\mathrm{p} \leq 0.05)$.

* Expresso em agliconas.

Os quatro tipos de PTS testados apresentaram variações nos teores de isoflavonas (Tabela 3) sendo que PTS 1 (112mg/100g) apresentou maior concentração de isoflavonas totais entre as PTS testadas. A PTS 2 pro- vem do mesmo fabricante das farinhas FS 1 e FS 2 e as diferenças observadas na concentração das isoflavonas podem ser devido às condições ambientais e genéticas sobre a matéria-prima, bem como as condições de processamento [17, 25], mas por se tratar de produtos comerciais, as informações que confirmam estas hipóteses são restritas.

No caso das PTS 3 e 4 as diferenças encontradas nos teores de isoflavonas se devem às condições de processamento: a PTS 3 foi produzida a partir de farinha de soja tostada e a PTS 4 de farinha de soja desengordurada, evidenciando que o desengorduramento promove concentração dos demais constituintes. As farinhas de soja FS 3, FS 4 e FS 5 e as PTS 3 e PTS 4 provém da mesma cultivar sob as mesmas condições ambientais durante o desenvolvimento dos grãos. A PTS 3 (68mg/100g), apresentou diferenças em relação à sua matéria-prima - farinha FS 3 (96mg/100g). Na farinha FS 3 os teores de conjugados $\beta$-glicosídicos e malonilglicosídicos em relação ao total de isoflavonas foram de $16 \%$ e $79 \%$, respectivamente, enquanto na PTS 3 os conteúdos passaram a ser de $57 \%$ e $29 \%$, respectivamente. A tostagem da farinha, bem como a extrusão com altas temperatura e pressão, favorecem a desesterificação dos conjugados malonil-glicosídios e formação de $\beta$-glicosídios [25]. Quanto aos teores de isoflavonas totais, a diferença entre FS 3 e a PTS 3 pode ser devido à formação de conjugados acetil-glicosídios, durante o processo de tostagem e extrusão. COWARD et al. [7], ao analisar produtos à base de soja concluíram que processos de aquecimento promovem descarboxilação de conjugados malonil originando conjugados acetil-glicosídios, pois estes são detectados apenas em produtos submetidos a tratamento térmico durante a produção. Ao extrusar uma mistura de milho e soja, MAHUNGU et al. [13], observaram que o aumento de temperatura e a diminuição da umidade promoveram diminuição de conjugados malonil-glicosídios e aumento proporcional de acetil-glicosídios, evidenciando a descarboxilação.

TABELA 3. Teor de isoflavonas (mg/l00g) em proteínas texturizada de soja (PTS).

\begin{tabular}{lccccccc}
\hline Produto & Daidzina & Genistina & $\begin{array}{c}\text { Malonil- } \\
\text { Daidzina }\end{array}$ & $\begin{array}{c}\text { Malonil- } \\
\text { Genistina }\end{array}$ & Daidzeína & Genisteína & Total $^{*}$ \\
\hline PTS 1 & $44,4 \mathrm{a}$ & $58,6 \mathrm{a}$ & $23,4 \mathrm{bc}$ & $40,7 \mathrm{c}$ & $7,5 \mathrm{a}$ & $8,2 \mathrm{a}$ & 112 \\
& $( \pm 1,2)$ & $( \pm 1,7)$ & $( \pm 0,8)$ & $( \pm 1,6)$ & $( \pm 0,3)$ & $( \pm 0,3)$ & \\
PTS 2 & $29,4 \mathrm{~b}$ & $35,1 \mathrm{bc}$ & $32,8 \mathrm{~b}$ & $38,6 \mathrm{c}$ & $3,8 \mathrm{~d}$ & $4,0 \mathrm{c}$ & 84 \\
& $( \pm 4,0)$ & $( \pm 3,9)$ & $( \pm 9,4)$ & $( \pm 4,7)$ & $( \pm 0,6)$ & $( \pm 0,5)$ & \\
PTS 3 & $25,5 \mathrm{~b}$ & $39,0 \mathrm{~b}$ & $19,9 \mathrm{bc}$ & $20,4 \mathrm{~d}$ & $4,8 \mathrm{bc}$ & $4,6 \mathrm{c}$ & 68 \\
& $( \pm 3,0)$ & $( \pm 3,9)$ & $( \pm 1,8)$ & $( \pm 2,8)$ & $( \pm 0,5)$ & $( \pm 0,4)$ & \\
PTS 4 & $17,5 \mathrm{c}$ & $30,4 \mathrm{c}$ & $50,9 \mathrm{a}$ & $63,1 \mathrm{a}$ & $4,1 \mathrm{~cd}$ & $5,6 \mathrm{~b}$ & 98 \\
& $( \pm 1,1)$ & $( \pm 0,6)$ & $( \pm 1,8)$ & $( \pm 1,5)$ & $( \pm 0,2)$ & $( \pm 0,1)$ & \\
\hline
\end{tabular}

Médias de três repetições e desvio padrão ( \pm DP), em base seca.

Médias seguidas pelas mesmas letras minúsculas nas colunas não diferem entre si pelo teste de Tukey $(\mathrm{p} \leq 0.05)$

Quanto ao teor de agliconas, a variação entre a farinha FS $3(4,1 \mathrm{mg} / 100 \mathrm{~g})$ e a PTS $3(9,5 \mathrm{mg} / 100 \mathrm{~g})$ pode ser devido à ação da enzima $\beta$-glicosidase sobre a dai- 
dzina e genistina durante o início do processo de tostagem da farinha para preparo da PTS, pois durante a extrusão a temperatura elevada inativa a enzima [13]. A enzima $\beta$-glicosidase apresenta atividade máxima a $50^{\circ} \mathrm{C}$ em pH 6,0, sofrendo inativação a $60^{\circ} \mathrm{C} \mathrm{[14].}$

Estudos recentes comprovam que a administração de isoflavonas purificadas produzem efeitos biológicos menos significativos quanto a redução do risco de doenças que àqueles produzidos pelo consumo de isoflavonas e proteínas da soja [3]. Atualmente, preconiza-se que a ingesta de $25 \mathrm{~g}$ de proteínas de soja associados a cerca de 30 a 50mg de isoflavonas diariamente são capazes de reduzir o colesterol sérico [19]. Considerando que as farinhas de soja integrais contêm em média $40 \%$ de proteínas as FS2, FS3, FS 4 e FS 5 contribuiriam entre 40 e $86 \mathrm{mg}$ de isoflavonas totais se a recomendação de consumo de $25 \mathrm{~g}$ de proteína de soja por dia fosse obedecida. A FS 1, desengordurada, em média 50\% de proteínas, contribuiria com $84 \mathrm{mg}$ de isoflavonas totais. Os PTS tem em média 50\% de proteína e o consumo de $25 \mathrm{~g}$ diárias de proteína, considerando os produtos analisados, pode contribuir entre 34 e $56 \mathrm{mg}$ de isoflavonas totais na dieta.

Considerando os benefícios das isoflavonas e das proteínas de soja à saúde humana, técnicas de processamento que otimizem a presença destes compostos em alimentos à base de soja devem ser estudados, considerando sobretudo o aumento da procura destes produtos por parte da população.

\section{2 - Formulados infantis e extratos hidrossolú- veis}

Os produtos FI 1, FI 2, FI 3 e FI 4 são formulados infantis que apresentam na composição outros ingredientes, como maltodextrinas, lecitina, óleo de soja refinado, sal, vitaminas e minerais, (informações dos rótulos) além de derivados de soja, fazendo com que a concentração de isoflavonas seja menor que a encontrada nos extratos EH 1 e EH 2 (Tabela 4). A adição de outras matérias-primas que não contêm isoflavonas na formulação dos alimentos, provoca a diluição destas, diminuindo sua concentração [24]. Segundo COWARD et al. [8] a adição de saborizantes como chocolate nos formulados à base de soja reduz em até 33\% a concentração de isoflavonas.

Dentre todos os produtos analisados, o formulado FI 1 apresentou o menor teor de isoflavonas pois produto foi obtido a partir de proteína isolada de soja. Segundo WANG \& MURPHY [24] isolados protéicos apresentam baixos teores de isoflavonas devido às perdas ocasionadas durante a extração, pois o $\mathrm{pH}$ alcalino pode modificar as cargas das moléculas de proteínas e alterar ligações com as isoflavonas. COWARD et al. [8] analisaram diferentes marcas de extratos hidrossolúveis e concluíram que extratos obtidos a partir de isolados protéicos de soja apresentam 4 vezes menos isoflavonas que àqueles preparados a partir de grãos de soja.
TABELA 4. Teor de isoflavonas (mg/100g) em formulados infantis (FI) e extratos hidrossolúveis (EH).

\begin{tabular}{cccccccc}
\hline Produto & Daidzina & Genistina & $\begin{array}{c}\text { Malonil- } \\
\text { Daidzina }\end{array}$ & $\begin{array}{c}\text { Malonil- } \\
\text { Genistina }\end{array}$ & Daidzeína & Genisteína & Total $^{*}$ \\
\hline FI 1 & $1,8 \mathrm{f}$ & $4,7 \mathrm{f}$ & $0 \mathrm{f}$ & $3,5 \mathrm{e}$ & $0 \mathrm{f}$ & $0 \mathrm{~g}$ & 6 \\
& $( \pm 0,1)$ & $( \pm 0,1)$ & & $( \pm 0,1)$ & & & \\
$\mathrm{FI} 2$ & $14,8 \mathrm{e}$ & $23,3 \mathrm{e}$ & $13,4 \mathrm{c}$ & $22,8 \mathrm{c}$ & $8,3 \mathrm{c}$ & $10,9 \mathrm{~b}$ & 67 \\
& $( \pm 1,2)$ & $( \pm 1,8)$ & $( \pm 1,2)$ & $( \pm 1,8)$ & $( \pm 0,6)$ & $( \pm 0,9)$ & \\
$\mathrm{FI} 3$ & $27,5 \mathrm{~d}$ & $32,5 \mathrm{~d}$ & $20,6 \mathrm{~b}$ & $35,2 \mathrm{~b}$ & $5,7 \mathrm{~d}$ & $7,4 \mathrm{cde}$ & 78 \\
& $( \pm 0,2)$ & $( \pm 0,1)$ & $( \pm 0,2)$ & $( \pm 0,1)$ & $( \pm 0,1)$ & $( \pm 0,1)$ & \\
$\mathrm{FI} 4$ & $36,9 \mathrm{c}$ & $56,1 \mathrm{c}$ & $13,0 \mathrm{c}$ & $22,9 \mathrm{c}$ & $7,7 \mathrm{c}$ & $9,6 \mathrm{bc}$ & 92 \\
& $( \pm 0,5)$ & $( \pm 1,3)$ & $( \pm 0,2)$ & $( \pm 0,7)$ & $( \pm 0,2)$ & $( \pm 0,2)$ & \\
& & & & & & & \\
$\mathrm{EH} 1$ & $91,3 \mathrm{a}$ & $108,5 \mathrm{a}$ & $28,3 \mathrm{a}$ & $44,6 \mathrm{a}$ & $10,5 \mathrm{~b}$ & $9,3 \mathrm{bcd}$ & 180 \\
& $( \pm 3,4)$ & $( \pm 4,7)$ & $( \pm 1,2)$ & $( \pm 1,9)$ & $( \pm 0,4)$ & $( \pm 0,4)$ & \\
EH 2 & $56,6 \mathrm{~b}$ & $67,5 \mathrm{~b}$ & $28,2 \mathrm{a}$ & $43,9 \mathrm{a}$ & $5,2 \mathrm{~d}$ & $4,8 \mathrm{f}$ & 123 \\
& $( \pm 0,8)$ & $( \pm 0,5)$ & $( \pm 0,1)$ & $( \pm 0,5)$ & $( \pm 0,4)$ & $( \pm 0,1)$ & \\
\hline
\end{tabular}

Médias de três repetições, em base seca.
Médias $( \pm D P)$ seguidas pelas mesmas letras minúsculas nas colunas não diferem entre si pelo teste de Tukey $(\mathrm{p} \leq 0.05)$.

entre si pelo teste de Tukey
$*$ Expresso em agliconas.

Nos extratos e formulados os principais isômeros são os $\beta$-glicosídios (Tabela 4). Durante o preparo de extratos de soja calor úmido é aplicado, levando a desesterificação dos conjugados malonil, diminuindo a concentração e aumentando a concentração dos $\beta$-glicosídios [8]. Durante o processo para produção de extratos de soja, compostos solúveis em água são separados dos resíduos insolúveis (okara) após cozimento e filtragem. WANG \& MURPHY [24] analisaram os constituintes químicos presentes no okara e, observaram quantidades insignificantes de isoflavonas, indicando que estas podem estar associadas a compostos solúveis, provavelmente proteínas.

WANG \& MURPHY [24], analisaram os 12 isômeros em extrato hidrossolúvel em pó e encontraram concentrações de isoflavonas totais expressas como agliconas que variavam entre $118 \mathrm{mg} / 100 \mathrm{~g}$ e $100 \mathrm{mg} / 100 \mathrm{~g}$. GENOVESE e LAJOLO [9] analisaram a presença dos 12 isômeros de isoflavonas em 6 marcas comerciais de alimentos infantis à base de soja e encontraram isoflavonas totais expressas como agliconas que variaram entre $7,4 \mathrm{mg} / 100 \mathrm{~g}$ e $24 \mathrm{mg} / 100 \mathrm{~g}$.

Nos extratos e formulados o teor das agliconas foi superior aos das farinhas de soja e PTS, variando de $8 \%$ a $28 \%$ do total de isoflavonas (exceto para o formulado FI 1 que não tinha agliconas). Os $\beta$-glicosídios, pela ação da enzima $\beta$-glicosidase, sob condições adequadas de temperatura e umidade podem sofrer hidrólise e dar origem as respectivas agliconas [2, 13]. Os extratos e formulados quando preparados conforme as especificações do rótulo terão concentrações de isoflavonas diferentes. Considerando as instruções de preparo as isoflavonas totais no formulado FI 1, após diluição do produto em $210 \mathrm{~mL}$ de água, será de $3,5 \mathrm{mg}$ e para os formulados FI 2 e FI 3 o teor de isoflavonas totais após diluição será de $28 \mathrm{mg}$ e $33,5 \mathrm{mg}$ em $180 \mathrm{~mL}$ de água, respectivamente.

A distribuição e a concentração de isoflavonas em alimentos à base de soja são importantes sobretudo 
quando estes são usados como alimentos funcionais na prevenção de doenças crônicas. Segundo BARNES, KIRK \& COWARD [4] a biodisponibilidade e o metabolismo das diferentes isoflavonas dependem da sua forma química, sendo as agliconas, sobretudo a genisteína, a isoflavona mais ativa na prevenção de diversos tipos de câncer hormônio-dependente [1].

\section{4 - CONCLUSÕES}

A distribuição dos isômeros e o teor total de isoflavonas nos produtos analisados variou em função das condições de processamento. Em farinha de soja e em proteína texturizada predominaram os compostos malonil-conjugados enquanto que em extratos hidrossolúveis e formulados infantis predominaram os $\beta$-glicosídios. Farinhas de soja obtidas a partir da mesma matéria-prima, mas submetidas a diferentes tratamentos térmicos apresentaram variações na distribuição dos isômeros, bem como na concentração total de isoflavonas. FS 3 e PTS 3 originados da mesma matéria-prima tiveram concentrações de isoflavonas totais diferentes $(96 \mathrm{mg} / 100 \mathrm{~g}$ e $68 \mathrm{mg} / 100 \mathrm{~g}$, respectivamente). Em formulados infantis à base de soja, o teor de agliconas foi proporcionalmente superior ao apresentado pelas farinhas analisadas, variando de $28 \%$ a $8 \%$ do total de isoflavonas.

\section{5 - REFERÊNCIAS BIBLIOGRÁFICAS}

[1] ANDERSON, J.W.; SMITH, B.M.; WASHNOCK, C.S. Cardiovascular and renal benefits of dry bean and soybean intake. The American Journal of Clinical Nutrition, v. 70, p. 464S-474S, 1999.

[2] ARAÚJO, J.M.A.; CARLOS, J.C.S.; SEDYAMA, C.S. Isoflavonas em grãos de soja: importância da atividade de b-glicosidase na formação do sabor amargo e adstringente. Ciênc. Tecnol. Aliment., v. 17, n. 2, p. 137$141,1997$.

[3] BADGER, T.M.; RONIS, M.J.J.; HAKKAK, R.; ROWLANDS, J.C.; KOROURIAN, S. The health consequences of early soy consumption. The Journal of Nutrition, v. 132, p. 559S-565S, 2002.

[4] BARNES, S., KIRK, M., COWARD, L. Isoflavones and their conjugates in soy foods: extraction conditions and analysis by HPLC-mass spectrometry. Journal of Agricultural and Food Chemistry, v. 42, p. 24662474, 1994.

[5] CARRÃO-PANIZZI, M.C.; KITAMURA, K.; BELÉIA, A.D.P.; OLIVEIRA, M.C.N. Influence of growth locations on isoflavone contents in Brazilian soybean cultivars. Breeding Science, v. 48, p. 409-413, 1998.

[6] CARRÃO-PANIZZI, M.C.; BELÉIA, A.D.P.; KITAMURA, K.; OLIVEIRA, M.C.N. Effects of genetics and environment on isoflavone content of soybean from different regions of Brazil. Pesquisa Agropecuária Brasileira, v. 34, n. 10, p. 1787-1795, 1999.

[7] COWARD, L.; BARNES, N.C.; SETCHELL, K.D.R.; BARNES, S. Genistein, daidzein, and their b-glycoside conjugates: antitumor isoflavones in soybean foods from American and Asian diets. Journal of Agricultural and Food Chemistry, v. 41, p. 1961-1967, 1993.

[8] COWARD, L.; SMITH, M.; KIRK, M.; BARNES, S. Chemical modification of isoflavones in soyfoods during cooking and processing. The American Journal of Clinical Nutrition, v. 68, p. 1486S- 1491S, 1998.

[9] GENOVESE, M.I.; LAJOLO, F.M. Isoflavones in soy based foods consumed in Brazil: levels, distribution, and estimated intake. Journal of Agricultural and Food Chemistry, v. 50, p. 5987-5993, 2002.

[10] KUDOU, S.; FLEURY, Y.; WELTI, D.; MAGNOLATO, D.; UCHIDA, T.; KITAMURA, K.; OKUBO, K. Malonyl isoflavone glycosides in soybeans seeds (Glicine max Merrill). Agriculture and Biological Chemistry, v. 55, n. 9, p. 2227-2233, 1991.

[11] KURZER, M.S.; XU, X. Dietary phytoestrogens. Annual Review Nutrition, v. 17, p. 353-381, 1997.

[12] LI, D., YEE, J.A.; McGUIRE, M.H.; MURPHY, P.A.; YAN, L. Soybean isoflavones reduce experimental metastasis in mice. The Journal of Nutrition, v. 129, n. 5, p. 1075-1078, 1999.

[13] MAHUNGU, S.M.; DIAZ-MERCADO, S.; LI, J.; SCHWENK, M.; SINGLETARY, K.; FALLER, J. Stability of isoflavones during extrusion processing of corn/ soy mixture. Journal of Agricultural and Food Chemistry, v. 47, p. 279-284, 1999.

[14] MATSUURA, M.; OBATA, A.; FUKUShimA, D. Objectionable flavor of soy milk developed during the soaking of soybeans and its control. Journal of Food Science, v. 54, n. 3, p. 602-605, 1989.

[15] MESSINA, M.; BARNES, S. The role of soy products in reducing risk of cancer. Journal National Cancer Institute, v. 83, n. 8, p. 541-546, 1991.

[16] MESSINA, M.; MESSINA, V. Increasing use of soyfoods and their potential role in cancer prevention. Journal of the American Dietetic Association, v. 91, p. 836840, 1991.

[17] MURPHY, P.A. Phytoestrogen content of processed soybean products. Food Technology, v. 36, p. 60-64, 1982.

[18] SAS INSTITUTE (1995), SAS proprietary software release 6.09. Cary, NC.

[19] SETCHELL, K.D.R. Phytoestrogens: the biochemistry, physiology and implications for human health of soy isoflavones. The American Journal of Clinical Nutrition, v. 68, p. 1333S-1346S, 1998.

[20] SONG, T.; BARUA, K.; BUSEMAM, G.; MURPHY, P.A. Soy isoflavone analysis: quality control and a new internal standard. The American Journal of Clinical Nutrition, v. 68, p. 1474S-1479S, 1998.

[21] THIAGARAJAN, D.G.; BENNINK, M.R.; BOURQUIN, L.D.; KAVAS, F.A. Prevention of precancerous colonic lesions in rats by soy flakes, soy flour, genistein, and calcium. The American Journal of Clinical Nutrition, v. 68, p. 1394S-1399S, 1998.

[22] TSUKAMOTO, C.; SHIMADA, S.; IGITA, K.; KUDOU, S.; KOKUBUN, M.; OKUBO, K.; KITAMURA, K. Factors affecting isoflavones content in soybean seeds: changes in isoflavones, saponins and composition of fatty acids at different temperatures during seed development. Journal of Agricultural and Food Chemistry, v. 43, p. 1184-1192, 1995.

[23] TUKEY, J.W. One degree of freedom for non-additivity. Biometrics, v. 5, p. 232-242, 1949.

[24] WANG, H-J.; MURPHY, P.A. Isoflavone content in commercial soybean foods. Journal of Agricultural and Food Chemistry, v. 42, p. 1666-1673, 1994.

[25] WANG, H-J.; MURPHY, P.A. Mass balance study of isoflavones during soybean processing. Journal of Agricultural and Food Chemistry, v. 44, p. 23772383, 1996. 